\title{
Pre-service Chemistry Teachers' Understanding About Equilibria in Acid-Base Solutions
}

\author{
Nejla Gültepe ${ }^{1 *}$ \\ ${ }^{1}$ Eskisehir Osmangazi University, Faculty of Education, Department of Mathematics and Science Education, Eskisehir, TURKEY \\ *Corresponding Author: nejlagultepe@gmail.com
}

Citation: Gültepe, N. (2021). Pre-service Chemistry Teachers' Understanding About Equilibria in Acid-Base Solutions. Pedagogical Research, 6(4), em0110. https://doi.org/10.29333/pr/11349

\begin{tabular}{|c|c|}
\hline ARTICLE INFO & ABSTRACT \\
\hline Received: 12 May 2021 & One of the complex units of chemistry education is acid-base equilibria, and learners have difficulty constructing \\
\hline Accepted: 16 Oct. 2021 & $\begin{array}{l}\text { cognitive structures on the subject. The aim of this study is to examine the conceptions of pre-service chemistry } \\
\text { teachers with regard to weak acid-base equilibria using a diagnostic test. A qualitative research method was } \\
\text { employed as the research design of the study. There were } 57 \text { pre-service chemistry teachers who were both } \\
\text { graduates of a chemistry department in a faculty of science and participants of postgraduate teacher training } \\
\text { programs in the study. The diagnostic assessment instrument was employed as a data collection instrument. The } \\
\text { data were subjected to content analysis and coding separated them into groups. Pre-service teachers' } \\
\text { conceptions were defined via these groups. In the study, two groups were determined: sound understanding and } \\
\text { rote learning. Two lower levels at the sound understanding level and four lower levels at the rote learning level } \\
\text { were also determined. These categories revealed the misconceptions of pre-service chemistry teachers with } \\
\text { regard to weak acid-base equilibria. It was observed that many pre-service teachers had immature cognitive } \\
\text { structures in respect to weak acid-base equilibria. }\end{array}$ \\
\hline
\end{tabular}

Keywords: acid-base equilibria, chemistry education, conceptual understanding, misconceptions, pre-service teachers

\section{INTRODUCTION}

Mental conceptions constitute either a knowledge linking or a knowledge structuring. The principal units of this relationship are conceptions (Doymus et al., 1998). Therefore, in order to comprehend scientific knowledge, obtaining accurate knowledge of conceptions is of vital importance. In order for meaningful learning to occur, the learner should have some relevant prior knowledge, and the teacher should establish a connection to guide the learner in noticing its relevance. In the cognitive sciences, the phrase "sound understanding" is commonly related to how concepts structured in a student's mind via model types in abstract situations, and above all, how these concepts are "linked" with each other. So, "sound understanding" implies the strong manifestation and connection of concepts. Numerous cognitive learning theorists highlight the positive connections between what has been learned and what is to be learned. They suggest that because of the logical and psychological connections of knowledge, convenient arrangements and presentations would increase the probability of sequential and vertical transfer of learning (Fensham, 1972; Kurt et al., 2013). Conversely, successive arguments built on rather unsteady knowledge lead to the shaping of poorly connected further concepts and rote learning rather than meaningful learning (Odabaşı Çimer \& Ursavaş, 2012; Sharma et al., 2013; Taber, 2001, 2005). It is not the lack of relevant prior knowledge but the disunity between existing prior knowledge and the newly-presented material which brings about fragmentation in learning. In a sense, when prior knowledge is lacking, learning cannot take place or it takes a long time to build links between existing cognitive structures and new information (Robertson, 1990). Researchers have continually emphasized the effectiveness of sound understanding as opposed to rote learning, which leads to a low probability of developing high-quality learning outcomes (Feng, 2005; Kılıç \& Sağlam, 2014). Williams and Cavallo (1995) found that a sound learning orientation establishes students' understanding, while a rote learning orientation leads to acquisition of more misconceptions. When students hold a sound understanding, they learn concepts by linking and relating new information to prior knowledge, and they obtain more meaningful understanding with regard to concepts. On the contrary, when students practice rote learning they can be expected to have problems in understanding concepts and may acquire misconceptions (Kıliç \& Sağlam, 2014). Learners' insufficient knowledge, inexperience in science education, naive thoughts, and lack of content knowledge or pedagogy may be the reasons for this (Coştu et al., 2007). However, while sound understanding is associated with the deep approach to learning, rote learning is associated with the surface approach (Dart \& Boulton-Lewis, 1998). In the surface approach, a task or assignment is undertaken because it is a designated assignment and the course cannot be 
passed if this assignment is not completed. Homework is uninteresting, so the least possible effort is put into the homework. There is no effort to understand key concepts. Instead, reliance is created by remembering model answers that are perceived as likely to appear in probable exams and tests, or as key facts. Concepts are not about personal experience; that is, it remains an abstract theory. As a result, whatever is memorized is normally quickly forgotten. However, a deep approach is taken when the student is interested in the subject or academic assignment. As a result, there is an attempt to understand the core concepts or underlying meaning of a topic. To constitute a meaningful whole, concepts will be associated with each other and new information will be associated with previous knowledge and personal experiences (Kember \& McNaught, 2007). Kember (2016) found in his study that students lack appropriate knowledge bases that are important for their performance in mathematics and science. The math and science curriculum is based on the building-block approach, in which the concept builds on what has been taught before. If concepts are not understood, memory-dependent comprehension will inevitably be poor.

Case and Marshall (2004) determined in their study that both algorithmic and procedural deep approaches focus on problem solving. The algorithmic approach involves defining and memorizing formulas and procedures to solve problems. Such an approach does not aim at understanding but involves some selective editing before memorization. The procedural deep approach uses procedures and algorithms to solve problems. However, students' intention is to reach an understanding of the concepts in the content of the problem. In mathematics, if the multiplication table is not learned then a calculation is difficult to do. Calculation becomes easier if procedures and formulas are memorized. But it is not easy if it is not accompanied by an understanding of the fundamental principles underlying the rules because it leads to a mechanistic algorithmic or procedural approach.

According to Schmidt (1997), that is one of the five major problems in the process of learning chemistry. He explained that symbolic representations in chemistry could give rise to misconception and confusions. Many of these occur at school because there are problems including particular terminology and the scientific language, especially if terms such as substances, particles and chemical symbols are not clearly distinguished. Gabel (1999) highlights that teachers prefer going from the macro level directly to the representational level and thus students have great difficulty in understanding concepts. Therefore it is essential to establish pre-service teachers' misconceptions related with pedagogical content knowledge. Pre-service teachers should be provided with fundamental knowledge and skills to instruct their own students during their teaching process to improve student learning, understanding and thinking skills. They should also encourage their students to employ their newly obtained knowledge and skills in different situations (Çimer, 2012). Thus, as Warburton (2008) puts forth, the process of pre-service education training is a convenient period to conduct interventions to bolster effective teaching through challenges and correcting pre-service teachers' own misconceptions to achieve the target results.

Acid-base equilibria is a concept which is abstract and complex in nature (Sheppard, 2006). Equilibrium in acid-base solutions is a very extensive subject that necessitates associations at the submicro and macro levels. The concept is also connected with introductory chemistry subjects such as the Le Chatelier principle, reaction rate, collision theory, particular nature of matter, chemical bonding, concentration units, solutions, and so forth, conceptually and algebraic analytically (Kousathana et al., 2005; Muchtar Harizal, 2012).

Science educators assert that most students have problems while building concepts in their minds and cannot link their previous knowledge of other chemistry topics with acid-base equilibria. Students in both secondary and higher education have a fractured conception of weak acid-base equilibria (Kousathana et al., 2005; Meyer, 2004) due to simply focusing on recalling the formulae without internalizing the cognitive aspects of connections weak acid-base solutions and dynamic equilibrium, or collision theory. This leads to misinterpretations or an incomplete understanding (Muchtar Harizal, 2012; Sheppard, 2006). According to Artdej et al. (2010), it is difficult for students to comprehend the concept of dissociation of weak acids and weak bases, dissociation of water, and the changes in concentration of $\mathrm{H}_{3} \mathrm{O}^{+}$and $\mathrm{OH}^{-}$in water. They claimed that observation reveals students'shortcomings in understanding the principles of chemical equilibrium. Observations show that students simply concentrate on the values and the mathematical formula given in the problem without thinking about what they have actually been required (Talanquer, 2006). Students often fall into traps by using generalizations learned by rote, which leads to misconceptions without understanding the basic concepts when they learn acid-base chemistry.

Scientific cohesive conception and formulas as a way of thinking in a logical and precise manner, but learners only establish systematic thinking for complex problem solving more abstractly with little or no relation to the directly observable universe (Prosser, 2008). Talanquer (2006) explained that students often make use of the same principles, strategies and interpretations automatically in solving different problems, and fail to consider other strategies and undervalue the nature of problems. Studies have shown that the ability of chemistry students to solve various problems correctly does not necessarily mean that they understand precisely the conceptual dimension of the event to which the problem is related (Dahsah \& Coll, 2008; Gültepe et al., 2013; Nakhleh, 1992;). Students memorize the solution to the problems and are able to solve similar problems in the same way. Nevertheless, they do not understand the event or the subject in the submicro world.

There are a number of studies in the literature that mention different aspects of comprehension of acids and bases (Cartrette \& Mayo, 2011; Chaiyapha et al., 2011; Sheppard, 2006). Demerouti et al. (2004) designed and made use of a questionnaire that had ten multiple-choice and eight open-ended questions. The questionnaire was administered to 119 twelfth grade Greek students. They discovered that the students had misconceptions and challenges on the following topics: definition of Bronsted-Lowry acids and bases, ionic equilibria, neutralization, $\mathrm{pH}$, and buffer solutions. Griffiths (1994) established fifteen misconceptions related to acid and bases. Five of them are connected with acid-base equilibria: a. more hydrogen gas is displaced from a strong acid because the strong one has more hydrogen bonds than a weak acid; b. all acids are strong and powerful; $c$. strong acids have a higher $\mathrm{pH}$ than weak acids do; $d$. neutralization is always concluded in a neutral solution; e. since a salt has neither a hydrogen nor a hydroxyl group, its solution cannot include neither hydronium nor hydroxide ions. Chaiyapha et al. (2011) suggest that more research 
should be conducted in this area, and they mention a number of topics where misconceptions are likely to occur such as confusion between acid-base strength and concentration, the hydrolysis of salts, the selection and the role of indicators in acid-base titrations, and the difference between equivalence and end points.

As in other chemistry subjects, I have observed that a remarkable majority of the high school students I have taught in algorithmic problem solving with the applications of Le Chatelier's principle in equilibrium reactions persistently solve it with a superficial procedural approach without trying to understand it, and then memorize this solution. When the structure of the questions was changed, they had difficulty or even failed in the solution. However, students who adopt a deep procedural approach after understanding the subject are successful by understanding this procedure and encoding it into memory or also by memorizing it. In fact, although those who do the coding process initially invest less time, they forget more quickly than the minority of students who do not memorize and instead understand deeply. Students who seek conceptual understanding are able to comprehend a topic with a later spiral in a better, deeper and more meaningful way, solving the questions by associating them with the previous topic, even though it takes a long time to solve them. Even though in explanation and interpretation questions, students answer the question "Which way will the system shift when the temperature is increased in the equilibrium reaction" as "to the side where the heat is present" or "the system will shift to the opposite side when a substance that is in the system is added", there were hardly any students who explained it in terms of the equality of the rates of the forward and reverse reactions or the balance between entropy and energy. In fact, not many people remember Le Chatelier's Principle completely and answer "whatever is increased shifts to the opposite side to decrease it". Students who apply the memorising approach have more difficulty in answering which direction the equilibrium reaction will shift with the volume change. A student adopted the memorising approach by saying that "when the volume increases, the number of moles in the reaction shifts to the side with more moles, know this, do not go into details, there is no need, this is enough for the exam" because this is what is required in the exam and it does not require effort. Students who learn chemical equilibrium in depth explain the weak acid/base equilibrium reactions through equilibrium theories in solving problems related to water ionization, titration, buffer and hydrolysis applications. This is very exciting. On top of all these, this study planned to investigate which approach the chemistry pre-service teacher adopted regarding weak acid/base equilibrium reactions. It focused on the models and theories that pre-service chemistry teachers apply while explaining about acid-base equilibria. In this context, the research sought an answer the following question: What is preservice chemistry teachers' understanding in respect to acid-base equilibria?

\section{METHODOLOGY}

Design and participants. A qualitative research design was employed in order to describe the understanding of pre-service chemistry teachers' ability to develop a deep understanding and to use scientific concepts and principles of acid-base equilibria to solve problems correctly. Qualitative research examines the subject with an interpretative and natural perspective and concentrates on more than one method. The prime aim in such research is to examine the subject in a detailed style. Hence it is essential to present the data in a detailed and direct way (Punch, 2005). In this respect, the research was conducted with 57 preservice chemistry teachers who were in the postgraduate teacher training program in the 2015-2016 academic year in Turkey. Formation is a postgraduate teacher training program where a teaching certificate is awarded after 9-months (pedagogical formation training for two terms), practice teaching courses for senior students (4th Grade) or graduates of undergraduate program in faculties of science of various universities. The first term of the program includes classroom management, teaching principles and strategies, assessment and evaluation courses; the second term includes special teaching methods and material design courses. Chemistry pre-service teachers also have to accomplish an internship period in secondary education schools with regard to the teaching application course, 6 course hours per week for 12 weeks

Instrument. The diagnostic assessment instrument was made up of two free response questions. The questions were given in Appendix 1. Opinions of a science education researcher and two chemistry teachers were sought to ensure content validity of the test. Two educators' opinions were received in terms of language and research suitability. The test was finalized after administering it to two chemistry postgraduates following the necessary changes made in the root of the second question in accordance with the views of the researcher and the chemistry teacher. The data obtained during the pilot study about the clarity and comprehensibility of the questions in the instrument were used during the process of shaping the interview form. The pilot study allowed the researchers to determine the response time of the test, the efficiency, and comprehensibility of the questions within the context of obtaining the target data. As a result of a study conducted with 41 pre-service teachers for the reliability of the test, the reliability of the test was found to be $\alpha=0.76$. Participants in the study were given 40 minutes to finish the test within a class hour.

Table 1 shows the strategies and comprehension levels based on the answers given by the pre-service teachers to the questions.

\section{FINDINGS}

We established the level descriptors through chemistry pre-service teachers in this study. The level descriptors employed in the form of frequency and percentage distribution are displayed in Table 2. 
Table 1. Comprehension levels and strategies to solve the problems

\begin{tabular}{|c|c|c|c|}
\hline Levels & Sub Levels & Approach & Criteria used to classify pre-service teachers \\
\hline \multirow[t]{2}{*}{$\begin{array}{l}\text { Sound } \\
\text { Understanding }\end{array}$} & Sound $(A)$ & $\begin{array}{l}\text { pure deep comprehension } \\
\text { building block more } \\
\text { conceptually and analytically in } \\
\text { details }\end{array}$ & $\begin{array}{l}\text { scientifically comprehend cause-effect relation with reaction rate and dynamic } \\
\text { equilibrium based conceptually at the molecular level in deep and procedural } \\
\text { set-ups all ones } \\
\text { correct solutions all ones } \\
\text { without misconceptions }\end{array}$ \\
\hline & Sound (B) & $\begin{array}{l}\text { understanding } \\
\text { more deep procedure for } \\
\text { settings step by step }\end{array}$ & $\begin{array}{l}\text { reasoning methods to predict cause-effect relationships between relevant } \\
\text { fundamental principles, chemical terms or facts and equations analytically and } \\
\text { algorithmically in details } \\
\text { correct solutions all ones } \\
\text { without misconceptions }\end{array}$ \\
\hline \multirow[t]{3}{*}{ Rote learning } & Rote $(A)$ & $\begin{array}{l}\text { surface and narrow approach } \\
\text { mechanical memorization }\end{array}$ & $\begin{array}{l}\text { memorization of fragmented knowledge with lack of procedural strategy } \\
\text { correct solutions all ones } \\
\text { without misconception }\end{array}$ \\
\hline & Rote (B) & $\begin{array}{l}\text { pure surface } \\
\text { memorization in parts }\end{array}$ & $\begin{array}{l}\text { employ some part of the questions correctly without procedural strategy and } \\
\text { understanding } \\
\text { incomplete correct answers with knowledge in parts } \\
\text { without misconception }\end{array}$ \\
\hline & Rote (C) & $\begin{array}{l}\text { pure surface } \\
\text { rote learning with } \\
\text { misconception }\end{array}$ & $\begin{array}{l}\text { have misconceptions } \\
\text { intuitive knowledge with memory }\end{array}$ \\
\hline
\end{tabular}

Table 2. Frequency and percentage distribution of pre-service chemistry teachers' answers

\begin{tabular}{ccccccccccccccc}
\hline & \multicolumn{2}{c}{ Sound A } & \multicolumn{2}{c}{ Sound B } & \multicolumn{2}{c}{ Rote A } & \multicolumn{2}{c}{ Rote B } & \multicolumn{2}{c}{ Rote C Answer } \\
\hline \multirow{2}{*}{ Question 1 } & $\mathrm{N}$ & $\%$ & $\mathrm{~N}$ & $\%$ & $\mathrm{~N}$ & $\%$ & $\mathrm{~N}$ & $\%$ & $\mathrm{~N}$ & $\%$ \\
& 2 & 3.5 & 5 & 8.8 & 2 & 3.5 & 8 & 14.0 & 36 & 63.2 & 4 & 7.0 \\
\hline Question 2 & 2 & 3.5 & 3 & 5.3 & 3 & 5.3 & 4 & 7.0 & 41 & 71.9 & 4 & 7.0 \\
\hline
\end{tabular}

Pre-service chemistry teachers are respected as holding a sound conceptual understanding when they have cohesive conception, are able to describe the concept correctly and scientifically, and possess the procedural and the cognitive abilities to employ the definitions of the concept in acid-base chemistry or related concepts like dynamic equilibrium correctly in problem solving. A pre-service chemistry teacher who uses a textbook for concept definition is considered as having rote or algorithmic understanding of the concept and memorization leads to a fragmented conception. Such a pre-service teacher probably has limited procedural skills to employ relational set-ups. It may be the case that he or she has never been introduced to another way of learning. Pre-service teachers who hold a misconception of a key concept may attach an inaccurate scientific meaning to the concept or may use the concept inaccurately in a relationship while solving problems. The answers of pre-service teachers for each question are shown in Table 3.

Findings about Question 1: Analysis of the pre-service teachers' answers for Question 1 are given below.

For Question 1 Part a and b, $3.5 \%(n=2)$, part c and d, 12.3\% $(n=7)$ pre-service teachers could respond correctly and scientifically. They provided a valid scientific definition and used the concepts accurately while responding. The pre-service teachers in Sound A group ( $3.5 \%, n=2)$ were able to express the change in the particle number by correctly interpreting Le Chatelier's principle for the weak acid. They could also define the changes in concentrations using the acidity constant formula through cognitive thinking skills. Sound B pre-service teachers $(8.8 \%, n=5)$ employ a deep approach while responding through analytical thinking skills algebraically.

The students having conceptions based on rote learning stated, "reaction shifts rightward, the concentration of products increases, that of reactant decreases". They actually explained the answer with the fragmented concept in which ionization percentage is low and Le Chatelier's principle in which equilibrium shifts to the side where particle number is low as a result of volume decrease by rote. However, since they could not connect the reason with the particular nature of matter, they were not able to employ their knowledge while solving unfamiliar problems with regard to the practice of Le Chatelier principle in weak acid-bases. Likewise, pre-service teachers who solved the problem uncomprehendingly could not give correct answers for Part a and b of the question; they responded to the question about the change in ionization percentage of pH employing word string, "as the acid is diluted, acidic property decreases" and "ionization percentage increases when the acid is diluted". The pre-service teachers in this group were considered as having the conventional knowledge available in books and courses but they appear to be incapable of associating concepts. The lack of meaningful learning of the concepts led to the incorrect solving of the problem. It was found that many pre-service teachers had misconceptions about acid-base equilibria: "when the acid is weak, no change occurs in the concentration." Two of them expressed the view that when water was added, the reactants of the reaction would be fluoride and hydrogen and therefore the reaction would shift to the hydrofluoric acid side. The misconceptions these pre-service teachers had in mind with regard to chemical equilibrium hindered them from learning the acid-base dynamic equilibrium concept meaningfully. 
Table 3. Pre-service teachers' conceptual understanding level

\section{Level of \\ understanding

sound

conceptual Approaches Response examples

Understanding
Sound $(A)$

*Sound (A) PT1: When the volume is doubled with regard to acidity constant formula, the reaction shifts towards products and the moles of hydronium and fluoride ions increase.

Rate of forward $=k_{f}[\mathrm{HF}]$ Rate of reverse $=k_{r}\left[\mathrm{H}^{+}\right]\left[\mathrm{F}^{-}\right]$

Collision reactant particles per volume $>$ Collision product particles per volume In other words, Rate of forward $>$ Rate of reverse

So, the number of product particles per volume must decreases more to equalize the rates of products, $M=n / v$; the concentrations of hydrogen and fluoride ions do not decrease twice since their moles increase as the volume doubles. As the moles of hydrogen fluoride decrease and the volume doubles, their concentrations decrease more than twice. Due to increasing the mole of hydrogen and fluoride and decreasing the mole of hydrogen fluoride, ionization percent of acid increases. When acid is diluted, its acidic property diminishes, $\mathrm{pH}$ increases (Answer for Question 1).

The base amount to neutralise hydrogen fluoride and hydrogen cyanide is equal because the concentrations and volumes of these acid solutions are the same and they are univalent. As base is dropped into the acid solution, the hydrogen ions in the solution neutralize the hydroxide ions. Because acids are weak, their ionization in water is reversible. The equilibrium shifts towards the right side as hydrogen ions decrease in time. Because the number of moles of the acids are equal, the required hydrogen moles for ionization are equal, as well. Therefore, the moles of hydroxide ions essential to neutralize the hydrogen ions will be the same.

There are equal moles of fluoride and cyanide ions. Both ions hydrolise in water to form their conjugate acid forms. $K_{a}$ of hydrogen fluoride is bigger than that of hydrogen cyanide. That means hydrogen fluoride is more of an electron acceptor than hydrogen cyanide in water, so cyanide ions are more basic than fluoride ions, because more electron donors. Consequently, the $\mathrm{pH}$ of hydrogen cyanide is bigger than hydrogen fluoride at equivalence point (Answer for question 2)

Sound (A) PT2: When water is added, the concentration of reagents and products will decrease. For reagents, the reaction slows down by $1 / 2$, for products, it slows down by $1 / 2 \times 1 / 2=1 / 4$. While reactants produce substances faster than products, the number of product moles increases and the number of reactive moles decreases. More product is obtained from fewer moles of reagent. In this case, there is an expected increase in the percentage of ionization. Hydrogen fluoride is a less ionized weak acid. The Ka value is much less. The moles of products do not increase by two times, because if they were to increase, then the reverse reaction rate would not change. The number of moles of acid is already decreasing. In other words, the molarity of all substances decreases and its speed also decreases. So the back reaction rate should decrease as well, allowing the equilibrium reaction to occur. In order for the $K_{a}$ value to remain unchanged, if the concentration of reactants decreases, mathematically the concentration of products must decrease. If the molarity of products decreases, the $\mathrm{pH}$ increases. (Answer for Question 1)

Equal moles of $\mathrm{NaOH}$ are required to neutralize the same moles of HF and HCN acids in equal volume solutions, because hydrogen ions will be formed in the products as much as the $\mathrm{NaOH}$ drops added. Both solutions will be depleted of acid and base, and there will be only ions in the solution. Fluoride and cyanide ion hydrolyze because it is the conjugate base of the weak acid. The cyanide ion is the stronger base; it accepts protons more easily from water. Therefore, its $\mathrm{pH}$ is greater. (Answer for Question 2)

\section{Sound (B) Sound (B) PT:}

$H F_{(l)} \Leftrightarrow H^{+}{ }_{(a q)}+F^{-}(a q)$

${ }_{n H F} / V \quad n_{H^{+}} / V \quad n_{F^{-}} / V$ (before dilution at first equilibrium)

$n \mathrm{HF}^{-}-\mathrm{a} / 2 \mathrm{~V} n_{H^{+}}+a / 2 V_{F^{-}}+a / 2 \mathrm{~V}$ (after dilution at second equilibrium)

$\left(n_{H^{+}}\right) / V \times\left(n_{F^{-}} / V\right) /\left(n_{H F} / V\right)=\left(n_{H^{+}}+a / 2 V\right) \times\left(n_{F^{-}}+a / 2 V\right) / n_{H F}-a / 2 V$

(Ka doesn't change)

All substances' concentration will decrease even if the mole of hydrogen ions and fluoride ions increase. The decrease in concentration due to increase in volume should be greater than the increase in concentration due to increase in moles, so that Ka does not change. Therefore $\mathrm{pH}$ increases. The ionization percentage increases because more ions are formed from the ionization of hydrogen fluoride in less moles. (Answer for Question 1) Two acids are weak and the number of their moles are equal. As the base is added, the acid and the basic salt and water are formed. Equal moles of $\mathrm{NaOH}$ are required to neutralize equal moles of acids, and the number of moles of salt is also equal. For example, one mole of salt is formed. Fluoride and cyanide ions are conjugate bases because their hydrolysis results in hydroxide ions.

$K_{\text {Hid }}=K_{\text {water }} / K_{a}$

The weaker an acid, the stronger its conjugate. The hydrolyze constant of the cyanide ion is greater and more basic than that of the hydrogen fluoride ion; its $\mathrm{pH}$ is lesser (Answer for Question 2)

Rote learning Rote (A) Rote (A) $\mathrm{PT}^{\star \star}$ : Since hydrogen fluoride is a weak acid, when it is diluted by adding water, forward reaction favors, reactant' mole number decreases, and products' mole number increases. Molarity of all decrease, not multiple times. $\mathrm{pH}$ increases. Molarity of the reactant decreases bigger than multiple times; that of products decrease smaller than multiple times. Therefore, ionization of percent increases when the weak acid is diluted (Answer for Question 1).

Since the concentrations and volumes of the acids are equal, the same amount of base is used to neutralize them. In the titration of weak acid and strong base, there is never a neutral medium; the solution has the properties of salt. Hydrogen cyanide is a weaker acid, with a smaller Ka. Since Hydrogen cyanide is a weaker acid, its salt is more basic and its $\mathrm{pH}$ is higher. (Question $2 b$ ) 


\begin{tabular}{|c|c|c|}
\hline $\begin{array}{l}\text { Level of } \\
\text { conceptual } \\
\text { understanding }\end{array}$ & Approaches & Response examples \\
\hline & Rote (B) & $\begin{array}{l}\text { Rote (B) PT1 }{ }^{\star \star} \text { : As hydrogen fluoride is a weak acid, HF is a weak acid, therefore it does not ionize } 100 \\
\% \text {. Besides, hydrogen fluoride has dissociation constants. The acidity decreases therefore when the } \\
\text { acid is diluted, pH of the solution increases and concentration of hydrogen ion decreases. As a weak } \\
\text { acid or base is diluted, ionization percent of the acid or the base increases (Answer for Question 1). } \\
\text { Hydrogen cyanide is weaker than hydrogen fluoride. More basic salt is produced, so pH of hydrogen } \\
\text { cyanide must be bigger. (Answer for Question for 2a) }\end{array}$ \\
\hline
\end{tabular}

Rote (B) PT2: HF $\rightarrow F+H$

As the volume increases, the concentration of all substances decreases. The percentage of ionization increases when water is added. The $\mathrm{pH}$ increases, as the concentration of the acid decreases (Answer for Question 1).

$\mathrm{HF}+\mathrm{NaOH} \rightarrow \quad \mathrm{HCN}+\mathrm{NaOH} \rightarrow$

$x \mathrm{~mol} \times \mathrm{mol} \quad x \mathrm{~mol} \times \mathrm{mol}$ (Answer for Question for 2a)

Rote Learning Rote (c) Rote (CPT1 $^{\star \star \star}$ : When the volume of hydrogen fluoride solution is doubled with water, the equilibrium

(procedural have misconception about shifts toward the ions; while the concentrations of hydrogen and fluoride ions double, that of

steps with equilibrium hydrogen fluoride drops in half. pH increases. (Answer for Question 1b)

misconception) Rote (CPT2: Concentration of acid and hydrogen ions decreases; moles of all species do not change (Answer for Question 1a).

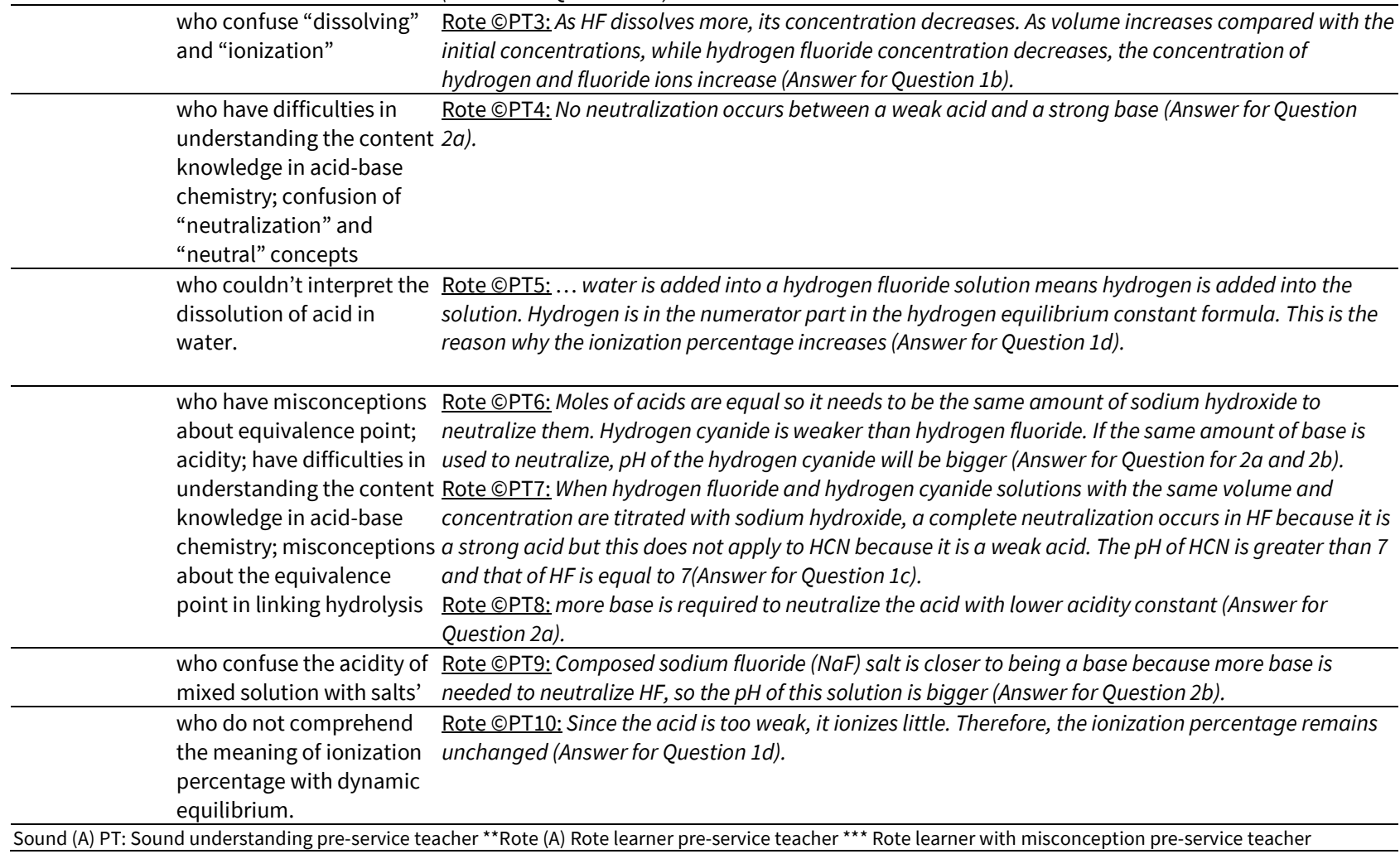

One of the important findings that should be highlighted is that most pre-service teachers did not answer the first and second part of the question. This indicated that Le Chatelier's Principle, the basis of the concept of chemical equilibrium, had not been understood and assimilated rightly at this particular level.

Findings about Question 2: All of the participants who answered managed to relate the acid strength, acidity constant and ionization percentage accurately. $52.6 \%(n=30)$ of them claimed that the acid with higher acidity constant would ionize more and thus the base that would neutralize the hydrogen ion that had been ionized before would be more. The pre-service teachers with rote conception had the fragmented knowledge that the acid with greater $\mathrm{K}_{\text {a }}$ value is stronger and can ionize more, and neutralization occurs in between hydrogen ion and hydroxide ion. Moreover, $7.0 \%(n=4)$ pre-service teachers holding algorithmic set-ups wrote neutralization reactions correctly, and they had the fragmented knowledge that the mole numbers of acid and base are equal at the equivalence point. But they could not link these notions with dynamic equilibrium, and so solved the problem inaccurately. They thought that the ionization reaction of the acids was the irreversible reaction. $8.8 \%$ ( $n=5)$ of them had the misconception that more base is required to neutralize the acid with the lower acidity constant. A pre-service teacher intuitionally speculated that the one with the low acidity constant would not be able to further the reaction, therefore more base had to be used. He related the $\mathrm{K}_{\mathrm{b}}$ value with the base amount required to neutralize the acid in the " $\mathrm{K}_{\mathrm{a}} \times \mathrm{K}_{\mathrm{b}}$ " formula.

Students had misconceptions about the definitions of the symbols and formulas of weak acids and bases and neutralization phenomenon. Five of them stated, "No neutralisation occurs" as they confused concepts of "neutralization" with "neutral." Three of them answered who had a sound conception of acid equilibrium but lacked a reference for reaction rate and collision theory. 


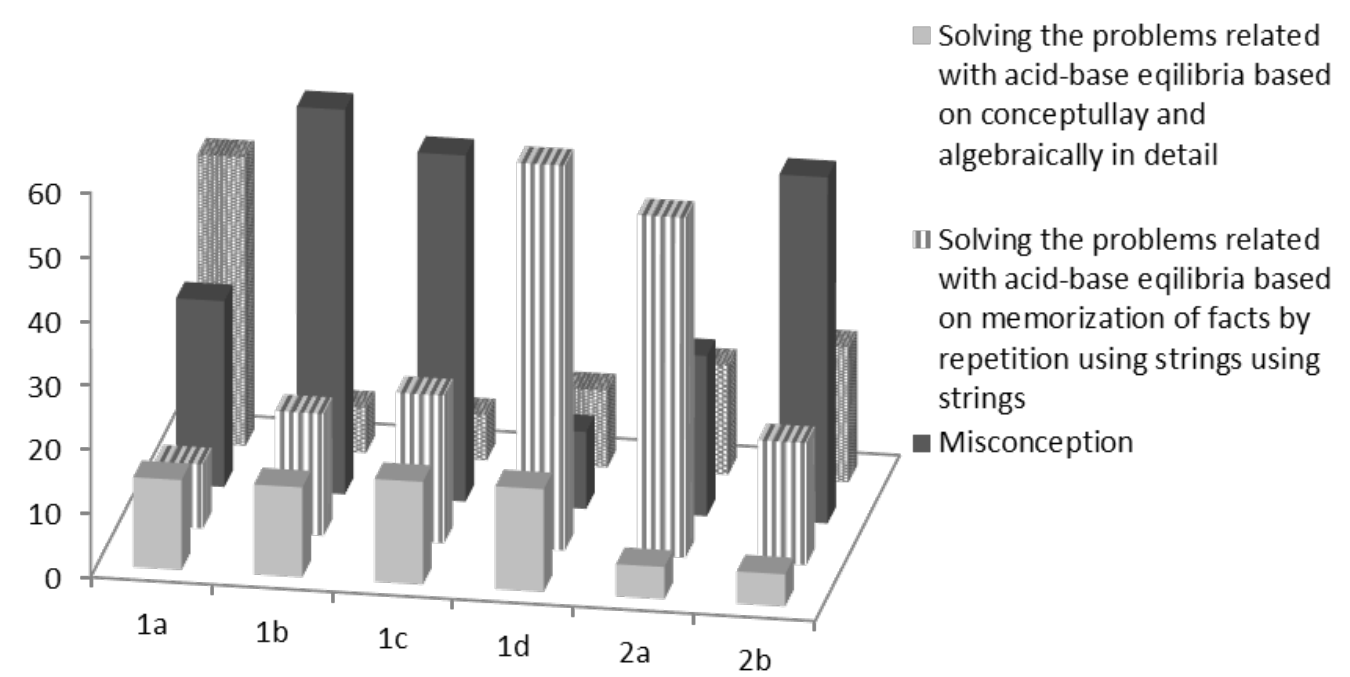

Figure 1. Percentage distribution of pre-service teacher answers with regard to Question 1 and Question 2

At the second part of Question 2, three pre-service teachers answered correctly that the $\mathrm{pH}$ of the one with low acidity constant at the equivalence point would be higher through ionization reaction and Le Chatelier principle. The pre-service teachers having cohesive conception could interpret their responses in a scientifically correct and explanatory manner. $54.4 \%$ of them were seen to have misconceptions about $\mathrm{pH}$ calculations in weak acid-strong base titration. For instance, two of them mentioned that the final solutions would be neutral. $8.77 \%(n=5)$ of the pre-service teachers stated that no neutralization would occur. $71.9 \%$ ( $n=41$ ) of them gave incorrect answers because they confused the acidity of the solution and the acidity of salt, and the concepts neutral and neutralization; they mixed acidity constant values; they could not identify with equivalence point and hydrolysis concept; and they had misconceptions about neutralization. The most important finding established at this stage about them was that only three of the pre-service teachers identified the conjugated base in the acid-base reaction and could relate it correctly to hydrolysis.

Two pre-service teachers associated both parts of the questions with titrations of weak acid solutions with base through dynamic equilibrium and Le Chatelier principle. Three pre-service teachers in the Sound B group explained hydrolysis in significant detail, even though they did not solve neutralization by relating it at a particular level. Figure 1 shows the frequency and percentage distribution with regard to the conceptual understanding level according to student responses for Question1 and Question 2.

\section{CONCLUSION AND DISCUSSION}

Faculty of Science, Department of Chemistry 4. With this program, it is aimed to increase the conceptual thinking and learning at the molecular level appropriate to the nature of the chemistry course, and to enable the studying or graduated pre-service teachers to adopt teaching practices and assessment approaches that will help sound understanding rather than a superficial approach. In this context, it is an important step to have knowledge about the level of understanding and mind models for the applications of principles, theories and rules. Evaluation studies conducted before and after teaching on subjects where preservice teachers are assumed to have a certain level of background are valuable in terms of drawing attention to the consciousness and awareness of students for their own learning and promoting meaningful learning outcomes. In the study, chemistry teacher pre-service teachers' understanding levels of solving problems on acid/base balance were depicted with intermediate levels between pure comprehending and pure memorizing poles.

The number of pre-service teachers with sound conception at an advanced level is lower in comparison to the number of teachers having other levels of conception. Those at this level correctly interpreted both questions and answered them in detail. Pre-service teachers in Sound $A$ level had a meaningful understanding and cohesive conception of the acid-base chemical concepts associated with the implementation of Le Chatelier's principle on weak acids and bases at a molecular level instead of memorized statements and formulas while solving chemistry problems. They managed to make associations with regard to the details of the acid-base equilibria concept and describe concepts with pure deep comprehension. $\mathrm{s}$ at this level had between 5 and 10 years of personal experience teaching chemistry in private courses. They reflected their experiences in the language they used in their answers: Emphasis on meaningful learning and deep approach, devaluing memorization.

In order for the pre-service teachers in Sound A to be able to make more pure conceptual comprehension and those in Sound $B$ to be able to make more strategic and analytic comments, an effort towards a good understanding of the subject in the learning process is essential. It can be said that one of the answers (Sound A) is learning for pure comprehension, and the other (Sound B) is one of the possible reflections of the process of developing a strategy for understanding and then memorizing. Sound B preservice teachers could accurately answer all ones and used relevant concepts in algorithmic and analytical set-ups. At this level, pre-service teachers reached the right solution with the facts, principles, terms and concepts they understood and the analytical strategies they coded in their own minds. Comprehension at this level is more meaningful than memorization in which solution 
and content bodies are brought together, as in rote learning levels; it instead requires competence and effort of understanding. It may also be said that Sound A-level teacher candidates adopt a more holistic approach while Sound B's adopt a more analytic approach. Also, a good memory of procedures and formulas will help with time-limited tests, including problems that require extrapolation.

Most of the students made generalizations in the process of chemistry learning. They just learned the formulae and theories given in the learning process by heart without understanding the underlying concepts. They just concentrated on memorizing the formulas and given theories without trying to comprehend them. Therefore, they tried to apply the same principles, strategies, and interpretations automatically while solving even different types of problems (Talanquer, 2006). A similar finding was encountered for the pre-service teachers in the current research.

The pre-service chemistry teachers at surface level (Rote A) concentrated on memorization of knowledge in parts without a series of steps. Due to the fragmented and limited knowledge they had, they generally have difficulties in expressing the background knowledge and defining the concepts. Therefore, they were unable to explain basic equilibrium principles. Pre-service teachers at Rote B level answered some of the questions with the few pieces of information they had by repeating the understanding associated with the question. One of the possible reasons for these pre-service teachers to partially or completely solve the questions with pieces of information may be their repetition and memorization efforts during the learning process.

Studies quoted in literature studies reveal that pre-service chemistry teachers do not understand chemistry concepts thoroughly, as is the case with students (Aydemir et al., 2008). Rather they misinterpreted the variables in the formula and symbols, and thus obtained the incorrect answer.

Chemical concepts should be approached as part of a network of interrelated ideas (Muchtar Harizal, 2012). Analysis of the responses of the pre-service chemistry teachers in the current study indicated that they possessed weak perceptions and misconceptions about acid-base equilibria that contribute to the literature. It was observed that the primary reason for this was the failure in linking chemical kinetics and chemical equilibrium in the micro world. Besides, misinterpretation of variables in formulas and symbols, and difficulties in understanding the content in acid-base chemistry were also observed. At school, science should be taught by exploring relationships and explanations between ideas and events, and understanding should be thorough (Devereux, 2007). The only way to achieve this is that all teachers personally have to understand science properly.

Chemistry curriculum and instruction should be based on the building-block approach, in which a concept is built on what has been taught before. The lack of effort and the memory-based understanding of previous concepts will inevitably render the foundations of learning new concepts unfounded. Students' lack of a suitable knowledge base will be evident in exams where practice and problem solving are tested, and especially where time limits are present. This is likely to be one of the reasons why students' chemistry course averages are low in exams.

A mass of evidence indicates that teachers' knowledge, understanding and thinking skills are connected with student learning and success (Hill et al., 2005). Therefore, education programs should dedicate time and effort to reveal and build on teachers' conceptions and establish their cognitive structures about concepts accurately, both their content knowledge and pedagogical content knowledge, in order to develop these conceptions during pre-service and in-service training (Inan, 2010; Valanides, 2000). Further study is needed to determine the factors behind pre-service chemistry teachers' misconceptions and their ability to successfully solve acid-base equilibria problems.

Funding: No funding source is reported for this study.

Declaration of interest: No conflict of interest is declared by author.

\section{REFERENCES}

Artdej, R., Ratanaroutai, T., Coll, R. K., \& Thongpanchang, T. (2010). Thai Grade 11 students' alternative conceptions for acid-base chemistry. Research in Science \& Technological Education, 28(2), 167-183. https://doi.org/10.1080/02635141003748382

Aydemir, N., Bektaş, O., Çetin-Dindar, A., Aydın, S., \& Boz, Y. (2008). Development of pre-service chemistry teachers' understanding of particulate nature of matter. A paper presented XIII. IOSTE Symposium September 21-26, Izmir, Turkey.

Cartrette, D., \& Mayo, P. (2011). Students' understanding of acids/bases in organic chemistry contexts. Chemistry Education Research and Practice, 12, 29-39. https://doi.org/10.1039/C1RP90005F

Case, J., \& Marshall, D. (2004). Between deep and surface: Procedural approaches to learning in engineering education contexts. Studies in Higher Education, 29, 605-615. https://doi.org/10.1080/0307507042000261571

Chaiyapha, P., Chayajarus, K., \& Chairam, S. (2011). Investigation of high school students' understanding of acid-base chemistry based on jigsaw method. In Pure and Applied Chemistry International Conference (pp. 139-142).

Coştu, B., Ayas, A., \& Ünal, S. (2007). Kavram yanılgıları ve olası nedenleri: Kaynama kavramı [Misconceptions and possible causes: Boiling concept]. Kastamonu Eğitim Dergisi [Journal of Kastamonu Education Faculty], 15(1), 123-136.

Çimer, A. (2012). What makes biology learning difficulties and effective: Students' views. Educational Research and Reviews, 7(3), 61-71.

Dahsah, C., \& Coll, RK. (2008). Thai grade 10 and 11 students' understanding of stoichiometry and related concepts. International Journal of Science and Mathematics Education, 6(3), 573-600. https://doi.org/10.1007/s10763-007-9072-0

Dart, B., \& Boulton-Lewis, G. (Eds.). (1998). Teaching and learning in higher education. Australian Council for Educational Research. 
Demerouti, M., Kousathana, M., \& Tsaparlis, G. (2004). Acid-base equilibria, Part II: Effect of developmental level and disembedding ability on students' conceptual understanding and problem solving ability. The Chemical Educator, 9, 132-137.

Devereux, J. (2007). Science for primary and early years: Developing subject knowledge. Sage Publications.

Doymuş, K., Canpolat, N., Pınarbaşı, T., Bayrakçeken, S., \& Gürses, A. (1998). Üniversite kimya bölümü öğrencilerinin bazı kimya kavramlarını anlama düzeyleri [Levels of some chemical concepts of students at chemistry departments of university]. Fen Bilimleri Eğitimi Sempozyumu [Science Symposium]. Karadeniz Technical University, Trabzon.

Feng, S.-L. (2005). Using ARCS Model to promote 11th graders' motivation and achievement in learning about acids and bases. International Journal of Science and Mathematics Education, 3(3), 463-484. https://doi.org/10.1007/s10763-004-6828-7

Fensham, P. J. (1972). Prior knowledge-a source of negative factors for subsequent learning. Research in Science Education, 2(1), 50-57. https://doi.org/10.1007/BF02558539

Gabel, D. (1999). Improving teaching and learning through chemistry education research: A look to the future. Journal of Chemical Education, 76, 548. https://doi.org/10.1021/ed076p548

Griffiths, A. K. (1994). A critical analysis and synthesis of research on students' chemistry misconceptions. In Schmidt, H.-J. (Ed.), Proceedings of the 1994 International Symposium on Problem Solving and Misconceptions in Chemistry and Physics (pp. 70-99). The International Council of Association for Science Education Publications.

Gültepe, N., Yalçın Çelik, A., \& Kılıç, Z. (2013). Exploring effects of high school students' mathematical processing skills and conceptual understanding of chemical concepts on algorithmic problem solving. Australian Journal of Teacher Education, 38(10), 106-122. https://doi.org/10.14221/ajte.2013v38n10.1

Hill, H. C., Rowen, B., \& Ball, D. L. (2005). Effects of teachers' mathematical knowledge for teaching on student achievement. American Educational Research Journal, 4(2), 371-406. https://doi.org/10.3102/00028312042002371

Inan, H.Z. (2010). Examining pre-school education teacher candidates' content knowledge and pedagogical content knowledge. Educational Sciences: Theory and Practice, 10(4), 2275-2323.

Kember, D. (2016). Why do Chinese students out-perform those from the West? Do approaches to learning contribute to the explanation? Cogent Education, 3(1), 1248187. https://doi.org/10.1080/2331186X.2016.1248187

Kember, D., \& McNaught, C. (2007). Enhancing university teaching: Lessons from research into award winning teachers. Routledge. https://doi.org/10.4324/9780203962947

Kılıç, D., \& Sağlam, N. (2014). Students' understanding of genetics concepts: the effect of reasoning ability and learning approaches. Journal of Biology Education, 48(2), 63-70. https://doi.org/10.1080/00219266.2013.837402

Kousathana, M., Demerouti, M., \& Tsaparlis, G. (2005). Instructional misconceptions in acid-base equilibria: An analysis from a history and philosophy of science perspective. Science and Education, 14(2005), 173-193. https://doi.org/10.1007/s11191-0055719-9

Kurt, H., Ekici, G., Aksu, Ö., \& Aktaş, M. (2013). Determining cognitive structures and alternative conception on the concept of reproduction (the case of pre-service biology teachers). Creative Education, 4(9), 572-587. https://doi.org/10.4236/ce.2013.49083

Meyer, H. (2004). Novice and expert teachers' conceptions of learners' prior knowledge. Science Education, 88, 970-983. https://doi.org/10.1002/sce.20006

Muchtar Harizal, Z. (2012). Analyzing of students' misconceptions on acid - base chemistry at senior high school in Medan. Journal of Education and Practice, 3(15), 65-74.

Nakhleh, M. (1992). Why some students don't learn chemistry: Chemical misconceptions. Journal of Chemical Education, 69(3), 191-196. https://doi.org/10.1021/ed069p191

Odabaşı Çimer, S., \& Ursavaş, N. (2012). Student teachers' ways of thinking and ways of understanding digestion and the digestive system in biology. International Education Studies, 5(3). https://doi.org/10.5539/ies.v5n3p1

Prosser, M. (2008). The scholarship of teaching and learning: What is it? A personal view. International Journal for the Scholarship of Teaching and Learning, 2(2), 2. https://doi.org/10.20429/ijsotl.2008.020202

Punch, K. F. (2005). Introduction to social research: Quantitative \& qualitative approaches. Sage.

Robertson, W.C. (1990). Detection of cognitive structure with protocol data: Predicting performance on physics transfer problems. Cognitive Science, 14, 253-280. https://doi.org/10.1207/s15516709cog1402_3

Schmidt, H. J. (1997). Students' misconceptions-Looking for a pattern. Science Education, 81, $123-135$. https://doi.org/10.1002/(SICI)1098-237X(199704)81:2<123::AID-SCE1>3.0.CO;2-H

Sharma, M. D., Stewart, C., Wilson, R., \& Gökalp, M. S. (2013). Can a syllabus change impact on students' perceptions of science? Fragmented and cohesive conceptions of physics. Eurasia Journal of Mathematics, Science \& Technology Education, 9(1), 3344. https://doi.org/10.12973/eurasia.2013.914a

Sheppard, K. (2006). High school students' understanding of titrations and related acid-base phenomena. Chemistry Education Research and Practice, 7(1) 32-45. https://doi.org/10.1039/B5RP90014J

Taber, K. S. (2001). Building the structural concepts of chemistry: some considerations from educational research. Chemistry Education: Research and Practice in Europe, 2(2), 123-158. https://doi.org/10.1039/B1RP90014E 
Taber, K. S. (2005). Learning quanta: Barriers to stimulating transitions in student understanding of orbital ideas. Science Education, 89(1), 94-116. https://doi.org/10.1002/sce.20038

Talanquer, V. (2006). Common sense chemistry: A model for understanding students' alternative conceptions. Journal of Chemical Education, 83(5), 811-816. https://doi.org/10.1021/ed083p811

Valanides, N. (2000). Primary student teachers' understanding of the particulate nature of matter and its transformations during dissolving. Chemistry Education: Research and Practise in Europe, 1(2), 249-262. https://doi.org/10.1039/A9RP90026H

Warburton, E.C. (2008). Changes in dance teachers' beliefs about critical thinking activities, Journal of Education and Human Development, 2(1), 116. https://doi.org/10.1080/15290824.2008.10387353

Williams, K. A., \& A. M. L. Cavallo. (1995). Reasoning ability, meaningful learning, and students' understanding of physics concepts. Journal of College Science Teaching, 24(5), 311-314. 
APPENDIX 1

1. When the volume of hydrofluoric acid is doubled through dilution; what changes occur in
a) the number of the ions of acid and hydrogen?
b) the concentration of the ions of acid and hydrogen?
c) $\mathrm{pH}$ ?
d) ionization percentage? $\left(\mathrm{K}_{\mathrm{a}}\right.$ for $\left.\mathrm{HF}=6.8 \times 10^{-4}\right)$

Give reasons for your answers for each in detail.

2. Two different solutions of monoprotic acids ( $\mathrm{HF}$ and $\mathrm{HCN}$ ) with the same concentrations and volumes whose $\mathrm{K}_{\mathrm{a}}$ values are known are titrated separately with some $\mathrm{NaOH}$ solution in both cases.

a) Compare the numbers of moles of $\mathrm{NaOH}$ required to neutralize these acids. Give your reasons.

b) Compare $\mathrm{pH}$ for both solutions at the equivalence points of their titrations. Give reasons for your answers. ( $\mathrm{K}_{\mathrm{a}}$ for $\mathrm{HF}=6.8 \times 10^{-4}$ and $\mathrm{K}_{\mathrm{a}}$ for $\mathrm{HCN}=6.2 \times 10^{-10}$ ) 